\title{
CORRESPONDENCE
}

These letters respond to the two Commentaries discussing 'Should scientists study race and IQ?' 'NO: Science and society do not benefit' by Steven Rose (Nature 457, 786-788; 2009) and 'YES: The scientific truth must be pursued' by Stephen Ceci and Wendy M. Williams (Nature 457, 788-789; 2009).

\section{The belief that genes cannot be changed is now outdated}

SIR - The relevance of race-andintelligence research is obvious. The most troubling feature of the world economy today is not the financial crisis, but the enormous difference in wealth, technological and cultural creativity, technical know-how and social organization between countries. The per-capita gross domestic product (GDP) is 30 times higher in the United States than in most African countries.

We do not know the reasons for the great divergence that created these inequalities, and without this knowledge we shall never be able to reverse them. Genetics is one hypothesis. It is also the one that can be tested most easily, with the aid of genome-wide association studies and whole-genome sequencing.

People have a strong desire to believe in a just world. The increasingly atheist intellectuals of the twentieth century gave up their belief in divine justice only to substitute for it the more 'scientific' belief that Mother Nature is just: that nobody is disadvantaged by his or her genes, and the undeniable inequities in the world are exclusively man-made. But the belief that individual differences in intelligence are unaffected by genes was shot down by a barrage of behaviour-genetic studies during the 1980s. Now science is threatening the very last bastion of the just-world belief: that Mother Nature cannot be blamed for inequities between entire nations and population groups.

By not investigating the race-intelligence link, we not only perpetuate ignorance and the prejudice that thrives on ignorance. We also deprive ourselves of the possibility to tackle the existing inequalities, first by a judicious development policy and - should genetic differences indeed be important - by eventually changing the allele frequencies of the offending genes. We should not get stuck in the twentiethcentury assumption that environments are changeable but genes are not. This will no longer be the case in the twenty-first century.

Investigations into the genetic aspects of race and intelligence are part of a wider enterprise in basic science: the study of the recent and ongoing evolution of human intelligence. This whole area of basic research will have to be scrapped if we refuse to study allele frequencies of cognition-related genes in human populations.

Gerhard Meisenberg Department of Biochemistry, Ross University School of Medicine, Picard Estate, Dominica, Windward Islands e-mail: GMeisenberg@rossmed. edu.dm

\section{Identifying adaptive differences could provide insight}

SIR - I agree with others who have said we should not expect different subgroups of the human population, evolving independently, to arrive at exactly the same place in terms of cognitive abilities. This makes no more sense than expecting different populations to end up identical in skin colour, stature, metabolism or other aspects that are easily understood as adaptations to different environments.

So, given that we have logical

reason to hypothesize about differences in cognitive abilities, why would we expect to measure these by using a single number such as $I Q$, which suggests there must be a hierarchy of cognitive function? The prediction surely is that each population will adapt to be better at the particular cognitive tasks that are most important for survival in its own environment. If this is the case, then identifying these (potentially adaptive) differences in cognitive ability, and searching for associations with genetic variants, could provide fascinating insights into how our brains work.

However, this is worlds away from measuring IQ of different 'race' groups in order to make claims about genetics and intelligence. There may be some value in these rather simplistic studies of race and IQ. But they do nothing to answer the scientific question of the genetic basis of intelligence and can easily be hijacked by individuals to advance their own prejudices.

Kathryn Holt Wellcome Trust Sanger Institute, Hinxton, Cambridge CB10 1SA, UK

e-mail:kh2@sanger.ac.uk

The arrogance of trying to sum up abilities in a number

SIR - Rose, Ceci and Williams ask whether scientists should study race and IQ. The problems with such studies seem to result, as they have done since the 1930s, from the near impossibility of defining the word 'intelligence'.

The introduction of IQ tests has always seemed to be one of the best examples of the great political and social harm that can be done by the mind-boggling arrogance of scientists who think that they can sum up human abilities in a single number.

The same sort of problem exists with the present generation of bibliometrists. So far they haven't managed to inflict as much damage but, left to themselves, they will.

David Colquhoun Department of Pharmacology, University College London, London WC1E 6BT, UK e-mail:d.colquhoun@ucl.ac.uk

\section{Is poverty better explained by history of colonialism?}

SIR - It is difficult to see the Commentary by Ceci and Williams as anything other than a whitewash. Decisions about what kinds of scholarly research questions and methods are considered worthy of attention and funding are fundamental to modern science.

Stupid science and evil science - both of which exist - should not be permitted to coexist casually alongside the normative intellectual activities we admire. It is the role of scientists, as gatekeepers, to distinguish among them, to identify them for non-specialist audiences and to repudiate the intellectually impoverished elements. Any science that fails to do this, that takes all work to be of equal stature, necessarily calls into question its own standing as a scholarly enterprise.

The study of an organic basis of intelligence is not itself threatening. But it does not explain economic stratification, poverty and illiteracy rates any better than the history of slavery and colonialism does. Anyone who thinks that it can is obliged to confront and acknowledge the political nature of the science 